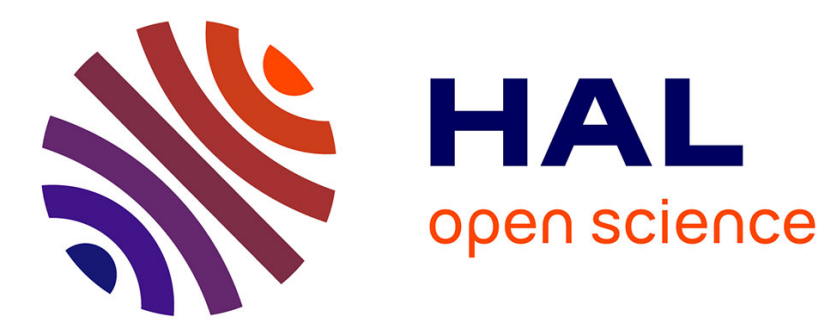

\title{
Connected heart rate sensors to monitor sleep quality: Electrodes, Chestbelt and smartwatch users acceptability
}

\author{
Mathieu Simonnet, Romain Billot, Bernard Gourvennec
}

\section{- To cite this version:}

Mathieu Simonnet, Romain Billot, Bernard Gourvennec. Connected heart rate sensors to monitor sleep quality: Electrodes, Chestbelt and smartwatch users acceptability . CHASE 2016: IEEE First Conference on Connected Health: Applications, Systems and Engineering Technologies, IEEE Computer Society, Jun 2016, Washington, Dc, États-Unis. pp.344 - 345, 10.1109/CHASE.2016.38 . hal-01359229

\section{HAL Id: hal-01359229 \\ https://hal.science/hal-01359229}

Submitted on 5 Sep 2016

HAL is a multi-disciplinary open access archive for the deposit and dissemination of scientific research documents, whether they are published or not. The documents may come from teaching and research institutions in France or abroad, or from public or private research centers.
L'archive ouverte pluridisciplinaire HAL, est destinée au dépôt et à la diffusion de documents scientifiques de niveau recherche, publiés ou non, émanant des établissements d'enseignement et de recherche français ou étrangers, des laboratoires publics ou privés. 


\title{
Connected heart rate sensors to monitor sleep quality
}

\author{
Electrodes, chest belt and smartwatch users acceptability
}

\author{
Mathieu Simonnet, Romain Billot \\ Télécom Bretagne, dpt LUSSI, \\ UMR CNRS 6285 / Lab-STICC \\ PLOUZANE, France \\ Mathieu.simonnet@telecom-bretagne.eu
}

\author{
Bernard Gourvennec \\ Télécom Bretagne, dpt LUSSI, \\ LOUSTIC \\ PLOUZANE, France \\ Bernard.gourvennec@telecom-bretagne.eu
}

\begin{abstract}
- 12 participants wore 3 different connected heart rate sensors during sleep (i.e. electrodes, chest belt, smartwatch). They consult the respective reports and filled a questionnaire to help us to identify which one is the most acceptable device to monitor sleep. Chest belt was perceived as the easiest device to use and was considered as reliable as electrodes. Taken together and in line with the Technology Acceptance Model, these preliminary results suggest that the chest belt is the most acceptable HR sensor device.
\end{abstract}

\section{Keywords—sleep, heart rate sensor, acceptability}

\section{INTRODUCTION}

The "PREventive Care Infrastructure based On Ubiquitous Sensing" (PRECIOUS) ${ }^{1}$ project aims to improve motivation to healthy life by providing the end-users with a lifestyle dashboard. The system collects information about the user from a variety of connected devices that measure food intake, physical activity, stress level and sleep quality.

"Sleep is a basic human need and is essential for good health, good quality of life and performing well during the day." [1]. The National Health and Nutrition Examination Survey (NHANES) has shown that $30 \%$ of adults reported less than 6 hours of sleep per night [2]. Although short sleep time is a well-known problem, few people are aware about the fluctuations of the recovery quality during sleep. However, today, this precious information can easily be available and consulted thanks to new connected heart rate (HR) sensors [3].

In this study we investigated whether the connected HR sensors are suitable to sleep with. More precisely we addressed the following issue: "Which of the electrodes, chestbelt and smartwatch is the most acceptable device to monitor sleep quality?"

\section{CONNECTED HEART RATE SENSORS}

$\mathrm{HR}$ data is fundamental to produce a relevant interpretation about sleep recovery [4]. HR variability (HRV) gives an insight about the sympathetic (activation) and parasympathetic (recovery) activities of the autonomic nervous system during sleep. There are currently three main types of connected HR sensors devices on the market.

\footnotetext{
${ }^{1} \mathrm{http}: / /$ www.thepreciousproject.eu/
}

Devices collecting ECG via electrodes (e.g. Firstbeat Bodyguard 2) are very accurate [5] and able to collect very long measurements regarding both the amount and accuracy of data and battery life.

Devices collecting ECG via chestbelt (e.g. Suunto smart sensor chestbelt) are designed to give information about and during exercise. However it could be worn for extended periods such as night. The data quality is typically good, except when the belt slips from the right position.

Devices collecting PPG are optical sensors (e.g. PulseOn). They measure HR by illuminating the blood vessels on a person's wrist with a LED in order to track blood flow. The measurement accuracy declines when a person is in motion, and it is less precise, generally speaking, because blood flow does not provide a distinct "peak" similar to an electrical signal originating from heart [6]. Optical sensors are thus less accurate than ECG-level devices. In addition, since the battery life is around 8 hours, depending on the user current HR, it can be a problem to monitor the complete night. Nevertheless optical sensors may be the most comfortable for the user during the night.

These three devices allow collecting HR. It is then possible to analyze HRV and provide the user with a report about his recovery during sleeping.

\section{ANALYTICS AND REPORTS}

Data collection is essential but analytics algorithms are needed to filter data and get rid of inconsistent signals.

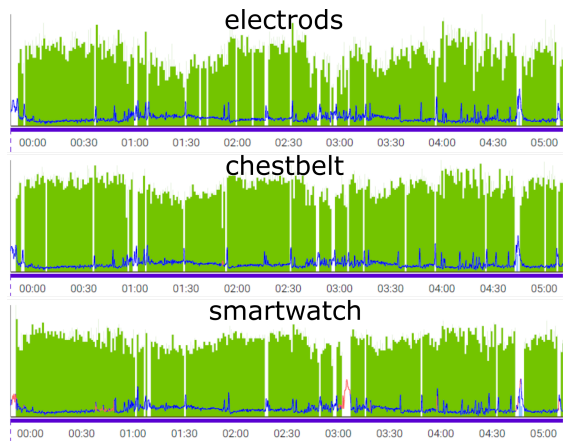

Figure 1: HR (blue line) and HRV (green area) from electrodes, chestbelt and smartwatch wear during the same night. 
To perform a quick test of the data reliability, one participant wore electrodes, chestbelt and smartwatch during the same night. After treatment, the electrodes report revealed $48 \mathrm{~ms}$ of HRV and $88 \%$ of recovery during sleep time, the chestbelt reports $87 \%$ and $48 \mathrm{~ms}$ and the smartwatch $88 \%$ and $51 \mathrm{~ms}$. These reports took great advantage of the data filtering since the HRV from smartwatch raw data took the inconsistent value of $174 \mathrm{~ms}$. The HRV from electrodes raw data was estimated at the plausible value of $51 \mathrm{~ms}$. However our main concern did not focus on objective data reliability but rather on participant's subjective perceptions.

\section{ACCEPTABILITY}

An appropriate device is a device that the user would accept to wear. Thus, we aim to assess the acceptability of the different types of devices. Technology Acceptance Model (TAM) has been used extensively in research looking at the acceptance of new technology [7]. The main idea of TAM is that a device is acceptable depending on the relationship between the "perceived usefulness" and the "perceived ease of use".

In this respect, the following experiment allowed us to gather first clues to address the research issue mentioned above.

\section{METHOD}

\section{A. Participants}

Even though this experimental protocol will be proposed to 32 people, until now, only 12 participants' results have been analyzed. This population is composed of 8 males and 4 females.

\section{B. Equipment}

Acceptabilities of the 3 following types of HR sensors were compared.

- The Firstbeat bodyguard 2 (2 points electrodes)

- The Suunto smart sensor (chestbelt)

- $\quad$ The PulseOn smartwatch (PPG)

\section{Situation}

Each participant first received instructions on how to use the device. Then she/he wore the sensor during the whole night. At the end, the HR report was generated and consulted by the participant with a specialist. Based on HRV analysis from the Firstbeat analytics algorithm, the report provided the users with their sleep time, the proportion of recovery during sleep and the quality of their recovery. Each participant tested the $3 \mathrm{HR}$ devices in a counterbalanced order.

\section{Data Collection}

At the end, participants filled a comparison's questionnaire to try to identify which device is more appropriate to sleep monitoring purpose.

\section{RESULTS \& DISCUSSION}

In brief, 12 participants slept with each device and consulted their respective reports. Then they filled in a questionnaire to help us to identify which device is the most acceptable to monitor sleep.

First of all, only 6 participants out of 12 found "useful" to use a heart rate sensor to monitor sleep activity. Here, interviews revealed that people who didn't experience sleep disorders do not need to monitor their night.

About ease of use, 7 participants found that the chestbelt is the easiest device to install, take off and charge. 3 persons claimed that the smartwatch is the easiest and 2 chose the electrodes as the easiest to use. Here the reason why the chestbelt got the best score is that the electrodes needed to be changed for each use and the smartwatch bracelet required to be tightened enough.

When we asked participant to check the device in which they trust, 10 participants out of 12 found that the electrodes and the chestbelt are reliable while only 4 claimed being confident with smartwatch data.

To date, chest belt is perceived as the easiest device to use and is considered as reliable as electrodes. Taken together and in line with the Technology Acceptance Model, these results suggest that the chest belt is the most acceptable HR sensor device. Even if this is consistent with participant's spontaneous verbalizations, this preliminary finding must be interpreted with cautious because only a third of the expected participants currently performed the experiment. Taking this limit into consideration, it is interesting to note that 6 participants claimed that they would prefer to use the chestbelt in the future.

\section{ACKNOWLEDGMENT}

Thanks to the European Commission for funding this project.

\section{REFERENCES}

[2] C. Schoenborn and P. Adams, "Health behaviors of adults: United States, 2005-2007.," Vital Health Stat. 10., no. 245, pp. 1-132, 2010 .

[3] S. T.-B. Hamida, B. AHMED, and D. Cvetkovic, "A new era in sleep monitoring: the application of mobile technologies in insomnia diagnosis," in Mobile Health, Springer International Publishing, 2015, pp. 101-127.

[4] T. Myllymäki, H. Rusko, H. Syväoja, T. Juuti, M.-L. Kinnunen, and H. Kyröläinen, "Effects of exercise intensity and duration on nocturnal heart rate variability and sleep quality," Eur. J. Appl. Physiol., vol. 112, no. 3, pp. 801-809, 2012.

[5] J. Parak and I. Korhonen, "Accuracy of Firstbeat Bodyguard 2 beatto-beat heart rate monitor," 2014.

[6] D.-G. Jang, S. Park, M. Hahn, and S.-H. Park, "A Real-Time Pulse Peak Detection Algorithm for the Photoplethysmogram," Int. J. Electron. Electr. Eng., vol. 2, no. 1, pp. 45-49, 2014. 